\title{
Growth of an anaerobic sulfate-reducing bacterium sustained by oxygen respiratory energy conservation after $\mathrm{O}_{2}$-driven experimental evolution
}

\author{
Marine Schoeffler, ${ }^{1}$ Anne-Laure Gaudin,,3 \\ Fanny Ramel, ${ }^{2}$ Odile Valette, ${ }^{2}$ Yann Denis, ${ }^{4}$ \\ Wagdi Ben Hania, ${ }^{1}$ Agnès Hirschler-Réa ${ }^{1}$ and \\ Alain Dolla ${ }^{10}{ }^{*}$ \\ ${ }^{1}$ Aix Marseille Université, Université de Toulon, CNRS, \\ IRD, MIO, Marseille, France. \\ ${ }^{2}$ Aix Marseille Université, CNRS, LCB, Marseille, France. \\ ${ }^{3}$ GERME SA, Technopôle de Château Gombert, \\ Marseille, France. \\ ${ }^{4}$ Aix Marseille Université, CNRS, IMM, Marseille, \\ France.
}

\section{Summary}

Desulfovibrio species are representatives of microorganisms at the boundary between anaerobic and aerobic lifestyles, since they contain the enzymatic systems required for both sulfate and oxygen reduction. However, the latter has been shown to be solely a protective mechanism. By implementing the oxygen-driven experimental evolution of Desulfovibrio vulgaris Hildenborough, we have obtained strains that have evolved to grow with energy derived from oxidative phosphorylation linked to oxygen reduction. We show that a few mutations are sufficient for the emergence of this phenotype and reveal two routes of evolution primarily involving either inactivation or overexpression of the gene encoding heterodisulfide reductase. We propose that the oxygen respiration for energy conservation that sustains the growth of the $\mathrm{O}_{2}$-evolved strains is associated with a rearrangement of metabolite fluxes, especially $\mathrm{NAD} / \mathrm{NADH}$, leading to an optimized $\mathrm{O}_{2}$ reduction. These evolved strains are the first sulfate-reducing bacteria that exhibit a demonstrated oxygen respiratory process that enables growth.

Received 9 February, 2018; revised 25 October, 2018; accepted 31 October, 2018. *For correspondence. E-mail alain.dolla@mio. osupytheas.fr; Tel. 33491828574; Fax 33486090641.

\section{Introduction}

Sulfate-reducing bacteria (SRB) are ubiquitously distributed anaerobic microorganisms that gain energy for growth by coupling the oxidation of organic compounds or molecular hydrogen with the reduction of sulfate to sulfide (Thauer et al., 2007). Despite the anaerobic nature of this metabolic process, SRB activity is not confined to permanently anoxic habitats since it has also frequently been found in biotopes that are temporarily exposed to oxygen (Canfield and Des Marais, 1991; Minz et al., 1999; Fourçans et al., 2008). Several types of ecological data, as well as impact studies of temporary oxygen stresses on various SRB (Marschall et al., 1993; Risatti et al., 1994; Krekeler et al., 1998; Fournier et al., 2006; Mukhopadhyay et al., 2007; Vita et al., 2008; Figueiredo et al., 2012; Ramel et al., 2013) demonstrated the aerotolerance capabilities of these bacteria with a higher oxygen tolerance for the members of the genus Desulfovibrio (Cypionka et al., 1985).

Desulfovibrio species have developed strategies to address the presence of oxygen and to protect themselves against its harmful effects, such as by the use of reactive oxygen species scavenging and oxygen consumption (Dolla et al., 2006). Oxygen consumption by Desulfovibrio species occurs in the three cell compartments. In the periplasm, this activity involves hydrogenases and c-type cytochromes (Baumgarten et al., 2001; Fournier et al., 2004). In the cytoplasm, rubredoxinoxygen oxidoreductase (ROO) is the terminal enzyme of a cytoplasmic NADH-linked chain that reduces oxygen in water (Chen et al., 1993; Frazão et al., 2000). Finally, in the membrane, this activity is performed by two oxygen reductases, a cytochrome $\mathrm{c}$ oxidase and a bd quinol oxidase, homologues of the enzymes found in aerobic microorganisms (Lemos et al., 2001; Santana, 2008; Lamrabet et al., 2011). A striking feature of these microorganisms is that they contain enzymes required for both sulfate and oxygen reduction (Lamrabet et al., 2011; Pereira et al., 2011). However, sulfate reduction is a true respiratory process that yields energy through oxidative phosphorylation to sustain growth (Thauer et al., 2007; Keller and Wall, 2011), while no growth dependent upon 


\section{M. Schoeffler et al.}

energy derived from oxygen reduction has ever been clearly demonstrated in pure Desulfovibrio cultures. Thus, oxygen reduction is thought to be a protective mechanism related to the high aerotolerance of these bacteria (Mukhopadhyay et al., 2007; Ramel et al., 2013; 2015).

Because of their enzymatic repertoire, Desulfovibrio species are good representatives of microorganisms at the boundary between anaerobic and aerobic respirations. In this study, we used the $\mathrm{O}_{2}$-driven experimental evolution of Desulfovibrio vulgaris Hildenborough $(D v H)$ to obtain additional insight into the ways by which this anaerobic microorganism copes with the presence of oxygen. We obtained evolved strains that could not only grow in the presence of a 32-fold higher $\mathrm{O}_{2}$ concentration than the maximal concentration tolerated by the ancestral $D v \mathrm{H}$ strain, but also utilize a true oxygen respiratory process to conserve energy to sustain growth in the total absence of sulfate. Two distinct routes of evolution to acquire this phenotype were observed with only a few mutations sufficient to permit the emergence of this new metabolic capability. We propose that metabolic flux rearrangement in the $\mathrm{O}_{2}$-evolved strains is the key mechanism that ultimately enables the optimization of $\mathrm{O}_{2}$ respiration to sustain growth.

\section{Results}

\section{$\mathrm{O}_{2}$-driven experimental evolution}

To investigate the adaptation strategy of $D v \mathrm{H}$ to oxidative conditions, a culture of a clonal isolate of the ancestral $D v \mathrm{H}$ strain (WTOR) was successively subcultured in lactate/sulfate medium under continuous oxygen sparging with $\mathrm{O}_{2}$ concentrations increasing from $0.02 \%$ to $0.65 \%$ (i.e., $0.23 \mu \mathrm{M}$ to $7.7 \mu \mathrm{M}$ dissolved $\mathrm{O}_{2}$ ) for a total of 114 generations. As a control, an aliquot of the WTOR culture was successively subcultured in lactate/sulfate medium under anaerobic conditions (Supporting Information Fig. S1) for the same number of generations. At the end, we obtained a population of $\mathrm{O}_{2}$-evolved cells able to grow to a final $\mathrm{OD}_{600 \mathrm{~nm}}$ of $\sim 1$ under continuous $0.65 \%$ $\mathrm{O}_{2}$-sparging while the control, a population of anaerobicevolved cells obtained after 114 generations, was unable to grow under this condition (Fig. 1A). Thus, $\mathrm{O}_{2}$-driven adaptive laboratory evolution permitted the selection of a $D v \mathrm{H}$ population exhibiting a greater aerotolerance than the WTOR strain. It should be noted that attempts to further increase the oxygen concentration in the gas mix for sparging were unsuccessful, suggesting that this $7.7 \mu \mathrm{M}$ of dissolved $\mathrm{O}_{2}$ is the maximum concentration tolerated by the evolved $D v H$ population under these growth conditions.
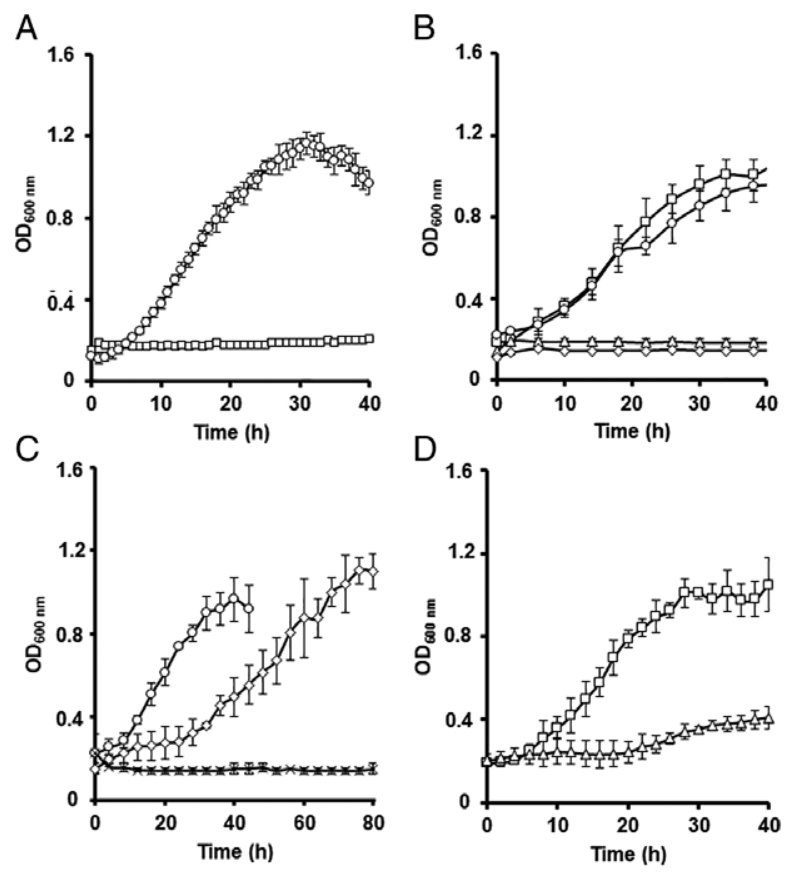

Fig. 1. Growth curves of the $\mathrm{O}_{2}$-evolved culture (circle), obtained after successive subcultures with stepwise increases of oxygen concentration for 114 generations, and anaerobic-evolved culture (square), obtained after successive subcultures under anaerobic conditions for 114 generations, in lactate/sulfate medium under continuous $0.65 \% \mathrm{O}_{2}$-sparging (A), of ES5 (circle), ESE (square), 114G2 (triangle) and WTOR (diamond) strains in pyruvate/sulfatefree medium under continuous $0.65 \% \quad \mathrm{O}_{2}$-sparging (B). Growth curves of ES5 (circle), DvH GEI ${ }^{-}$(cross), $\mathrm{GEI}^{-} \Delta h d r A$ (diamonds) strains (C), as well as ESE (square) and ESE $\Delta h d r A$ (triangle) strains (D) in pyruvate/sulfate-free medium under continuous $0.65 \%$ $\mathrm{O}_{2}$-sparging. The growth curves of the isolated strains were obtained from at least four independent experiments. Error bars are the SDs in the measurements.

Twenty-five clones from the $\mathrm{O}_{2}$-evolved population (ES strains) were randomly selected after plating under anaerobic conditions and re-grown in liquid lactate/sulfate medium under continuous $0.65 \% \mathrm{O}_{2}$-sparging conditions. At the same time, five clones from the anaerobic-evolved population (114G strains) were also randomly selected after plating under anaerobic conditions and re-grown in liquid lactate/sulfate medium under anaerobic conditions. All 25 ES strains grew to a final $O_{600 n m}$ of $\sim 1$ under continuous $0.65 \% \mathrm{O}_{2}$-sparging conditions while none of the five $114 \mathrm{G}$ strains nor the WTOR did (data not shown).

\section{Genotypic characterization}

As a first step, the expression of genes encoding known oxygen reductase enzymes in $\mathrm{DvH}$ (Dolla et al., 2006) in the isolated strains was analysed by qPCR. Surprisingly, some of the strains lacked an amplification signal corresponding to the roo1 gene (DVU2014) encoding a ROO. The presence of the roo1 gene was confirmed in only 
6 of the 25 ES strains (data not shown). The roo 1 gene is located in a genomic island (GEI) and it has been shown that the GEI can be excised and lost during successive cultivation of $D v H$ (Johnston et al., 2009). Absence of the roo1 gene can be thus related to the absence of the GEI in these ES strains. Thus, $24 \%$ of the ES strains isolated (6 out of 25) contained the genomic island GEl, while $76 \%$ (19 out of 25) lacked it. This showed that the $\mathrm{O}_{2}$-evolved population obtained at the end of the $\mathrm{O}_{2}$-driven adaptive laboratory evolution was composed of a mixture of $\mathrm{GEI}^{+}$and $\mathrm{GEI}^{-}$cells. To assess the distribution of these two genotypes during the course of the $\mathrm{O}_{2}$-driven adaptive laboratory evolution, the number of copies of the roo1 gene, located within the GEl, was quantified by qPCR and related to that of the roo2 gene (DVU3185), located outside the GEI.

The number of copies of roo1 relative to the number of copies of roo2 in the WTOR culture was close to 1 (Fig. 2), showing that the ancestral clonal $D v \mathrm{H}$ strain was $\mathrm{GEI}^{+}$. However, this number drastically decreased during the first steps of the $\mathrm{O}_{2}$-driven adaptive evolution to only approximately 0.2 after 44 generations in the culture exposed to continuous $0.12 \% \mathrm{O}_{2}$-sparging conditions. In contrast, this ratio was approximately one in the anaerobic-evolved culture after 114 generations (Fig. 2). Thus, the decrease in frequency of the GEI in the $\mathrm{O}_{2}$-evolved population was triggered by the presence of oxygen and occurred early along the course of the $\mathrm{O}_{2}$-driven adaptive laboratory evolution.

The genomes of six ES strains, three containing the GEl, namely, ESC, ESD and ESE, as well as three that lacked it, namely, ES3, ES4 and ES5, were sequenced using Illumina

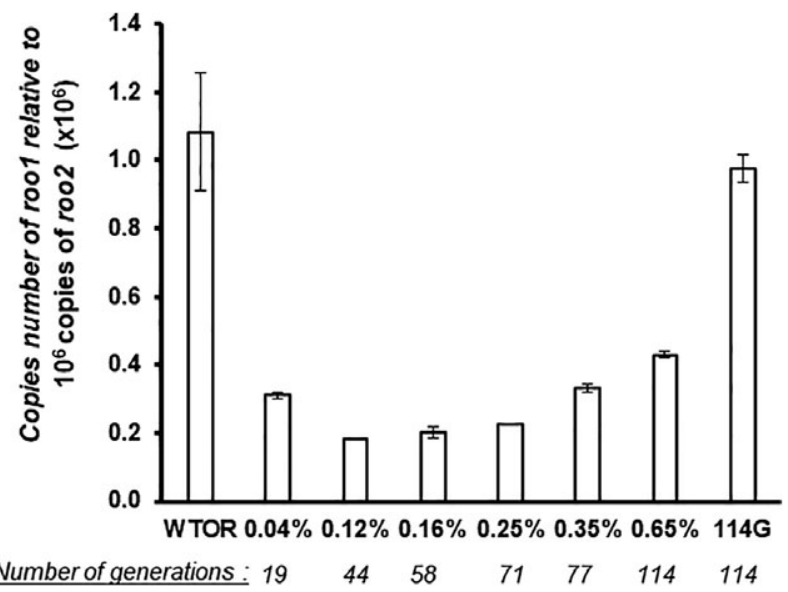

Fig. 2. Quantification of the copies of the roo1 (DVU2014) gene relative to the roo2 (DVU3185) gene by qPCR. The numbers of copies of roo1 are normalized to $1 \mathrm{E}+06$ copies of roo2. The percentages indicated correspond to the oxygen concentration applied during the course of the $\mathrm{O}_{2}$-driven evolution. Error bars are the SDs in the measurements $(n=3)$. WTOR corresponds to the ancestral $D v H$ strain, and $114 \mathrm{G}$ corresponds to the anaerobic-evolved culture after 114 generations. technology. The genomes of three $114 \mathrm{G}$ strains (114G1, $114 \mathrm{G} 2$ and 114G3) and of the ancestral $D v \mathrm{H}$ strain (WTOR) were also sequenced (Supporting Information Table S1). Comparative analysis with the $\mathrm{NCBI}$ reference $\mathrm{DvH}$ sequence NC_002937.3 (Heidelberg et al., 2004) led to the identification of several single nucleotide polymorphisms (SNPs) and insertion/deletion (InDels) mutations.

Mutations found in WTOR genome compared with the NCBI reference DvH sequence NC_002937.3 (Supporting Information Table S2) were shared by the ES and 114G strains. They were excluded from the analysis, since they represented mutations resulting from the propagation of the $\mathrm{DvH}$ strain in the laboratory for years. In contrast, mutations exclusively found in the ES and $114 \mathrm{G}$ strains were considered to be the result of $\mathrm{O}_{2}$ driven and anaerobic adaptive laboratory evolutions respectively. Among them, eight polymorphic loci in the WTOR at low frequencies (below 0.05 from NGS data) but homogenous alleles in the isolated ES or $114 \mathrm{G}$ strains were identified (Table 1). This suggested that these pre-existing mutations were under selection during the laboratory evolution experiment. Considering the mutations shared by all the ES strains but not present in the $114 \mathrm{G}$ strains, two distinct genotypes were revealed and thus could account for the observed phenotype of growth under continuous $0.65 \% \mathrm{O}_{2}$-sparging. One genotype, corresponding to strains ES3, 4 and 5, was characterized by the absence of the GEI, a point mutation in the hdrA gene (DVU2402) inducing a frameshift in the coding region and an insertion upstream from the transcriptional start of DVU1690, which encodes a transcriptional regulator, TetR. Further analysis by PCR genotyping showed that these mutations were present in all the plate-isolated strains that did not contain the GEl. The second genotype, corresponding to strains ESC, D and E, was characterized by the presence of the GEI and the deletion of four nucleotides upstream of DVU1690. This deletion was confirmed in all the plate-isolated ES strains that contained the GEI. It should be noted that the mutation in the hdrA gene (DVU2402) was from the pre-existing polymorphisms in the ancestral $D v \mathrm{H}$ strain while both mutations upstream from the DVU1690 gene were new mutations that appeared early during the course of the $\mathrm{O}_{2}$-driven evolution (detectable in the culture under $0.04 \% \mathrm{O}_{2}$ sparging) (Supporting Information Fig. S2).

The $\mathrm{O}_{2}$-driven experimental evolution allowed us to obtain evolved strains of $D v H$ with greater aerotolerance than the WTOR strain, after the limited number of 114 generations and only a limited number of genomic mutations. These strains can grow under continuous $0.65 \%$ oxygen-sparging corresponding to $7.7 \mu \mathrm{M}$ of dissolved oxygen at $33{ }^{\circ} \mathrm{C}$, approximately 32 -fold higher than the maximal concentration tolerated by the ancestral DvH strain (Ramel et al., 2015). Phenotypes of the ES5 


\section{M. Schoeffler et al.}

Table 1. Mutations identified in $\mathrm{O}_{2}$-evolved ESC, D, E, ES3, 4 and 5 strains and anaerobic-evolved strains $114 \mathrm{G} 1,2$ and 3 strains compared with the ancestral $D v H$ (WTOR) strain used for evolution.

\begin{tabular}{|c|c|c|c|c|c|c|}
\hline Strain & $\begin{array}{l}\text { Mutation } \\
\text { type }\end{array}$ & $\begin{array}{l}\text { Mutation } \\
\text { position }\end{array}$ & Affected gene(s) & $\begin{array}{l}\text { Genomic } \\
\text { localization }\end{array}$ & $\begin{array}{l}\text { Nucleotide } \\
\text { change }\end{array}$ & $\begin{array}{l}\text { Amino-acid } \\
\text { change }\end{array}$ \\
\hline \multirow[t]{2}{*}{$\mathrm{ESC} / \mathrm{D} / \mathrm{E}$} & $\begin{array}{l}\text { Deletion } \\
\text { Deletion }\end{array}$ & $\begin{array}{l}\text { Intergenic } \\
\text { Gene }\end{array}$ & $\begin{array}{l}\text { DVU1690, tetR, transcriptional regulator } \\
\text { DVU3134, glpK, glycerol kinase }\end{array}$ & $\begin{array}{l}1768101 \\
3282104^{*}\end{array}$ & $\begin{array}{l}\text { TAACA } \rightarrow \text { T } \\
\text { TC } \rightarrow \text { T }\end{array}$ & $\begin{array}{l}\text { Non-coding }(-75) \\
-82 \text { amino acids }\end{array}$ \\
\hline & SNPa & $G_{e n e}{ }^{a}$ & DVU0171, patB, hemolysin related protein ${ }^{\mathrm{a}}$ & $213843^{\mathrm{a}}$ & $A \rightarrow G^{a}$ & $\mathrm{Val} \rightarrow \mathrm{Ala}^{\mathrm{a}}$ \\
\hline \multirow[t]{2}{*}{$\mathrm{ES} 3 / 4 / 5$} & $\begin{array}{l}\text { Insertion } \\
\text { Deletion } \\
\text { Insertion }\end{array}$ & $\begin{array}{l}\text { Gene } \\
\text { Gene } \\
\text { Intergenic }\end{array}$ & $\begin{array}{l}\text { DVU2402, } h d r A \text {, heterodisulfide reductase A } \\
\text { DVU3134, g/pK, glycerol kinase } \\
\text { DVU1690, tetR, transcriptional regulator }\end{array}$ & $\begin{array}{l}2507946^{*} \\
3281432^{\star} \\
1768033\end{array}$ & $\begin{array}{l}T \rightarrow T A G \\
A G \rightarrow A \\
\text { Duplication of region } \\
\quad 1768033 \text { to } \\
\quad 1768116\end{array}$ & $\begin{array}{l}-514 \text { amino acids } \\
-282 \text { amino acids } \\
\text { Non-coding (-143) }\end{array}$ \\
\hline & $\mathrm{SNP}^{\mathrm{b}}$ & Gene $^{\mathrm{b}}$ & DVU0126, ABC transporter ${ }^{\mathrm{b}}$ & $159851^{\mathrm{b}}$ & $T \rightarrow G^{b}$ & Leu $\rightarrow \mathrm{Arg}^{\mathrm{b}}$ \\
\hline \multirow[t]{2}{*}{$114 \mathrm{G} 1 / 2 / 3$} & $\begin{array}{l}\text { Insertion } \\
\text { SNP } \\
\text { SNP } \\
\text { SNP } \\
\text { Insertion }\end{array}$ & $\begin{array}{l}\text { Intergenic } \\
\text { Gene } \\
\text { Intergenic } \\
\text { Gene } \\
\text { Gene }\end{array}$ & $\begin{array}{l}\text { DVU0435, hypothetical protein } \\
\text { DVU0681, sensor histidine kinase } \\
\text { DVU1941, HAD superfamily hydrolase } \\
\text { DVU1941, HAD superfamily hydrolase } \\
\text { DVU3134, glpK, glycerol kinase }\end{array}$ & $\begin{array}{l}489733^{\star} \\
755786 \\
2014879^{\star} \\
2014855^{\star} \\
3281945^{\star}\end{array}$ & $\begin{array}{l}G \rightarrow G A \\
C \rightarrow T \\
G \rightarrow A \\
G \rightarrow A \\
T \rightarrow \text { TGGTA }\end{array}$ & $\begin{array}{l}\text { Non-coding }(+9) \\
\text { Ala } \rightarrow \text { Thr } \\
\text { Non-coding }(-13) \\
\text { Asp } \rightarrow \text { Asp } \\
-181 \text { amino acids }\end{array}$ \\
\hline & $\begin{array}{l}\text { SNP }^{c} \\
\text { Deletion }^{c}\end{array}$ & $\begin{array}{l}\text { Gene }^{c} \\
\text { Gene }^{c}\end{array}$ & $\begin{array}{l}\text { DVU1469, ribosomal protein } \mathrm{S}^{\mathrm{C}} \\
\text { DVU3134, glpK, glycerol kinase }^{\mathrm{c}}\end{array}$ & $\begin{array}{l}1551147^{\mathrm{c}} \\
3281991^{\mathrm{c} *}\end{array}$ & $\begin{array}{l}\mathrm{C} \rightarrow \mathrm{T}^{\mathrm{c}} \\
\mathrm{CGA} \rightarrow \mathrm{C}^{\mathrm{c}}\end{array}$ & $\begin{array}{l}\text { Gly } \rightarrow \text { Arg }^{\mathrm{c}} \\
-92 \text { amino acids }\end{array}$ \\
\hline
\end{tabular}

Grey highlights mutations common within ESC/D/E, ES3/4/5 or 114G1/2 strains.

$(\mathrm{nb})$ corresponds to the localization of the mutation when intergenic compared with the start codon $(-\mathrm{nb})$ or compared with the stop codon (+nb). (-XXX) amino acids corresponds to the number of suppressed amino acids due to the deletion. Abbreviation: SNP: single nucleotide polymorphism.

${ }^{a}$ Mutation found exclusively in ESD strain.

${ }^{\mathrm{b}}$ Mutation found exclusively in ES3 strain.

${ }^{\mathrm{C}}$ Mutations found exclusively in 114G3 strain.

${ }^{*}$ Pre-existing polymorphism in the WTOR.

and ESE strains, which were selected as representatives for each $\mathrm{O}_{2}$ emerging genotype, were then compared with those of the anaerobic-evolved 114G2 and ancestral WTOR strains.

\section{Phenotype of the $\mathrm{O}_{2}$-evolved strains in lactate/sulfate medium}

Growth parameters of the strains under various conditions (Supporting information Figs S3 and S4) are summarized in Table 2.

The final biomass of the $\mathrm{O}_{2}$-evolved strains grown with $0.65 \% \mathrm{O}_{2}$, measured as the final $\mathrm{OD}_{600 \mathrm{~nm}}$, and growth rates in lactate/sulfate medium, were as high as those of the ancestral WTOR and 114G2 strains grown under anaerobic conditions (Table 2, Supporting Information Fig. S3). It should be noted that cell counting by microscopy revealed a similar number of cells per $\mathrm{mL}$ for a given $\mathrm{OD}_{600 \mathrm{~nm}}$ (1 unit at $\mathrm{OD}_{600 \mathrm{~nm}}$ corresponding to $7.21 \pm 1.13$ $10^{8}$ cell $\mathrm{mL}^{-1}$ ) regardless of the strain or the growth conditions (i.e., $\mathrm{O}_{2}$-sparging or anaerobic conditions). As expected, at the end of growth, the ESE strain cultured with $\mathrm{O}_{2}$ consumed almost all the lactate, similar to the WTOR and 114G2 strains cultured under anaerobiosis. In the case of the ES5 strain, approximately $15 \%$ of the lactate remained (Supporting Information Fig. S5A). The molar growth yield on lactate $\left(Y_{\text {lac }}\right)$ was slightly higher for the ES5 and ESE strains than for WTOR (Supporting Information Fig. S5B). The metabolism of the $\mathrm{O}_{2}$-evolved strains when grown with $\mathrm{O}_{2}$ appeared to be as efficient as that of the ancestral WTOR strain grown under anaerobic conditions, indicating that the $\mathrm{O}_{2}$-evolved strains were well-adapted to the oxidative conditions. Interestingly, the

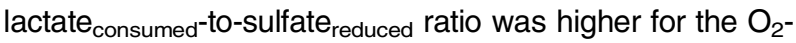
evolved strains grown with $\mathrm{O}_{2}$ than for the WTOR and 114G2 strains under anaerobic conditions (Supporting Information Fig. $\mathrm{S} 5 \mathrm{C}$ ), suggesting that the $\mathrm{O}_{2}$-evolved strains used $\mathrm{O}_{2}$ as an alternative electron acceptor in addition to sulfate.

To confirm this hypothesis, the cells were grown in lactate/sulfate-limiting medium (37 $\mathrm{mM}$ lactate/9 $\mathrm{mM}$ sulfate) (Supporting Information Fig. S3). As expected, the final biomass for all the type strains cultured under anaerobiosis was lower than that reached when sulfate was not limiting. Interestingly, both the biomass and growth rate of the ES strains were significantly higher when cultured with $\mathrm{O}_{2}$ than under anaerobic conditions (Table 2). At the end of the growth, sulfate was completely consumed in all the cultures (data not shown). Under oxygen sparging conditions, sulfate was consumed throughout the duration of the growth, explaining the lack of diauxic growth kinetics (Supporting Information Fig. S6). It should be noted that thiosulfate or sulfite could not be detected by ion chromatography. When $250 \mu \mathrm{M}$ molybdate, an inhibitor of sulfate 
reduction (Newport and Nedwell, 1988), was added to the medium, the final biomass when both the ESE and ES5 strains were cultured under continuous $0.65 \%$ oxygensparging was quite similar, while it was drastically reduced when the strains were cultured under anaerobic conditions, corresponding to only $48 \%$ and $51 \%$ of the final biomass in the absence of molybdate for ESE and ES5 respectively (Supporting Information Fig. S7).

It has been observed that some Desulfovibrio strains developed atypically elongated cells when grown in the presence of oxygen (Sass et al., 1998) and in a recent study, we showed that when $D v \mathrm{H}$ was cultured in lactate/ sulfate medium under continuous $0.02 \% \mathrm{O}_{2}$ sparging, the median length of the cells increased by $0.23 \mu \mathrm{m}$ (Ramel et al., 2015). Analysis of the cell length by TEM showed that, when cultured under anaerobic conditions, the length distribution of the WTOR and the ES cells were comparable with a median value of $1.27 \mu \mathrm{m}, 1.43 \mu \mathrm{m}$ and $1.20 \mu \mathrm{m}$ for the WTOR, ES5 and ESE cells, respectively, while the median length of the $114 \mathrm{G} 2$ cells was higher $(2.01 \mu \mathrm{m})$. When grown under continuous $\mathrm{O}_{2}$-sparging, the median cell lengths of the ES5 and ESE cells shifted to larger values, $+0.39 \mu \mathrm{m}$ and $+0.36 \mu \mathrm{m}$ respectively (Supporting Information Fig. S8). As for $D v \mathrm{H}$ cultured under constant low oxygen sparging $\left(0.02 \% \mathrm{O}_{2}\right)$ (Ramel et al., 2015), culturing the $\mathrm{O}_{2}$-evolved strains under continuous $0.65 \% \mathrm{O}_{2}$ sparging induces comparable morphological changes that are reversible when the cells are grown under anaerobic conditions.

Growth of the ES strains with $\mathrm{O}_{2}$ as the terminal electron acceptor

Cultivation of the ES strains was attempted with lactate as carbon and energy sources and oxygen as the electron acceptor in sulfate-free medium. In this medium, sulfur source is provided by the yeast extract. However, all the assays were unsuccessful, regardless of the addition of strong reducer such as cysteine- $\mathrm{HCl}, \mathrm{Na}_{2} \mathrm{~S}$ or titanium citrate. Since the standard free energy of pyruvate dehydrogenation is approximately 11 -fold lower than that of lactate (Thauer et al., 1977), growth assays in sulfatefree medium were performed using pyruvate instead of lactate as electron donors. Remarkably, the growth of both ES5 and ESE strains in the total absence of sulfate under continuous $0.65 \% \mathrm{O}_{2}$-sparging were observed with a maximal $\mathrm{OD}_{600 \mathrm{~nm}}$ obtained after approximately $40 \mathrm{~h}$ at $33{ }^{\circ} \mathrm{C}$, while neither WTOR nor the 114G2 strain grew during the same time period (Fig. 1B and Table 2). In the absence of both oxygen and sulfate, no growth was observed by any strain (ES, 114G or WTOR) during the same time period (Table 2, Supporting Information Fig. S4). Because during pyruvate fermentation, the produced $\mathrm{H}_{2}$ could inhibit the growth, cultures were 


\section{M. Schoeffler et al.}

attempted under continuous $\mathrm{N}_{2}$-sparging $\left(40 \mathrm{ml} \mathrm{min}^{-1}\right)$ to lower the $\mathrm{H}_{2}$ partial pressure in the medium. However, none of the strains grew during the same time period $(40 \mathrm{~h})$. It should be noted that the final biomass when the ESE and ES5 strains were cultured in pyruvate/sulfatefree medium under continuous $0.65 \% \mathrm{O}_{2}$-sparging was similar without and with addition of $250 \mu \mathrm{M}$ molybdate. As molybdate inhibition control, under anaerobic conditions in pyruvate/sulfate medium, the final biomasses obtained with ESE and ES5 were much lower in the presence of $250 \mu \mathrm{M}$ molybdate than it is absence $(64 \%$ and $71 \%$ lower respectively) (Supporting Information Fig. S7). Because the strains were stored frozen in lactate/sulfate, it is conceivable that some hydrogen sulfide could be added to the medium with the inoculum even if two successive subcultures were preliminary performed in pyruvate/sulfate-free medium. Hydrogen sulfide concentrations in the ES5 and ESE cultures just after inoculation were $0.01 \pm 0.01 \mathrm{mM}$ and $0.03 \pm 0.02 \mathrm{mM}$ respectively. Thus, this very low $\mathrm{H}_{2} \mathrm{~S}$ concentration at the inoculation time could not account for the observed growth of the ES strains in pyruvate/sulfate-free medium under continuous oxygen sparging via the biological or abiotic sulfide oxidation that would occur (Fuseler et al., 1996; Luther et al., 2011). End-product analysis by HPLC of pyruvate metabolism revealed that acetate was the only organic acid detected. Neither fumarate, formate, succinate nor ethanol, proposed as possible end-products of pyruvate fermentation in addition to acetate in D. vulgaris Hildenborough (Voordouw, 2002; Ramos et al., 2015) or D. alaskensis G20 (Meyer et al., 2014) could be detected under any growth conditions (i.e., in the presence of sulfate under anaerobic conditions or in its absence under continuous $\mathrm{O}_{2}$-sparging). The addition of $6 \mathrm{mM} \mathrm{KCN}$, an inhibitor of the membrane-bound oxygen reductases (Ramel et al., 2013), in the culture medium completely inhibited the growth of both strains in pyruvate/sulfatefree medium under continuous $0.65 \% \quad \mathrm{O}_{2}$-sparging while the final biomass was similar for both strains in pyruvate/sulfate medium under anaerobic conditions with or without the addition of KCN (Supporting Information Fig. S9).

The energy derived from pyruvate oxidation, measured as the intracellular ATP concentration in mid-log phase cells, was approximately three times higher when the ES strains were cultured with $\mathrm{O}_{2}$ in the absence of sulfate than when they were cultured anaerobically in the presence of sulfate (Fig. 3). The expected free energy change of the oxygen-dependent pyruvate oxidation (Eq. 1) $\left(\Delta G^{\prime 0}=-284.5 \mathrm{~kJ} \mathrm{~mol}^{-1}\right.$ of pyruvate) is 3.3-fold more exergonic than that of the sulfate-dependent pyruvate oxidation (Eq. 2) $\left(\Delta G^{\prime 0}=-85.3 \mathrm{~kJ} \mathrm{~mol}^{-1}\right.$ of pyruvate) (Thauer et al., 1977).
$\mathrm{CH}_{3} \mathrm{COCOOH}+0.5 \mathrm{O}_{2}+\mathrm{H}_{2} \mathrm{O} \rightarrow \mathrm{CH}_{3} \mathrm{COOH}+\mathrm{HCO}_{3}{ }^{-}+\mathrm{H}^{+}$

$\mathrm{CH}_{3} \mathrm{COCOOH}+0.25 \mathrm{SO}_{4}^{2-}+\mathrm{H}_{2} \mathrm{O}$
$\rightarrow \mathrm{CH}_{3} \mathrm{COOH}+\mathrm{HCO}_{3}^{-}+0.75 \mathrm{H}^{+}+0.25 \mathrm{HS}^{-}$

Considering the energy required to synthesize ATP from ADP and inorganic phosphate [approximately $75 \mathrm{~kJ} \mathrm{~mol}^{-1}$ (Thauer et al., 1977)], more ATP could be synthesized when using $\mathrm{O}_{2}$ as an electron acceptor instead of sulfate. These theoretical values are in complete agreement with the intracellular ATP concentrations experimentally measured that are greater in the ES strains cultured with $\mathrm{O}_{2}$.

These phenotypic analyses of the $\mathrm{O}_{2}$-evolved strains in sulfate-free medium unambiguously demonstrate that they respire oxygen as a true respiratory process and gain sufficient energy through oxidative phosphorylation to sustain growth.

\section{Mechanism of evolution}

To obtain deeper insights into the manner by which the $\mathrm{O}_{2}$-evolved strains were able to grow by respiring oxygen, the expression level of the genes encoding bd quinol oxidase, cytochrome c oxidase and ROO was analysed by qPCR. It revealed that only the transcription of the bd genes was increased in both the ES5 and ESE strains $[4.4 \pm 0.5$ and $6.3 \pm 0.6$ times (mean $\pm S D$, $n=9$ ) respectively] compared with the WTOR strain. The oxygen consumption activities of the cells were measured. The overall oxygen consumption activities in the washed whole cells with lactate as an electron donor were $25.14 \pm 4.59,22.36 \pm 4.50$ and $25.50 \pm 3.55 \mathrm{nmol}$ $\mathrm{O}_{2}$ consumed $/ \mathrm{min} / \mathrm{mg}$ protein for the WTOR, ES5 and ESE strains respectively. Despite the bd gene upregulation, no significant increase in the $\mathrm{O}_{2}$ consumption activity was measured in the ES strains compared with the WTOR strain. It had been proposed previously that the accumulation of internal carbon reserves can be used as reducing power to reduce oxygen in Desulfovibrio gigas (Santos et al., 1993). However, no polyglucose granules such as those found in D. gigas (Hensgens et al., 1996) could be detected by electronic microscopy in the ES strains (data not shown).

According to the genome sequencing results, only a limited number of mutations accounted for the $\mathrm{O}_{2}$ respiratory growth of the ES5 and ESE strains. To determine whether the absence of the GEI and/or inactivation of the $h d r A$ gene was sufficient to confer this new capability to the ES5 strain, the growth behaviours of both the $D v \mathrm{H}$ $\mathrm{GEl}^{-}$(Johnston et al., 2009) and its derived $\Delta h d r A$ 
deletion mutant strains were studied in the presence of oxygen. As shown in Fig. $1 \mathrm{C}$, the $D v \mathrm{H} \mathrm{GEI}^{-}$strain was unable to grow in pyruvate/sulfate-free medium under continuous $0.65 \% \quad \mathrm{O}_{2}$-sparging, while the $\mathrm{GEI}^{-} \Delta h d r A$ strain grew, although more slowly than the ES5 strain. These observations suggest that in the $\mathrm{GEI}^{-}$genetic context, the inactivation of HdrA is critical to permit the cells to respire oxygen for growth. However, this mutation is not sufficient alone to stabilize this metabolic capability over successive subculturings, suggesting that, in addition, fine metabolic tuning is required.

Since HdrA was critical for oxygen respiration in the ES5 strain, the expression level of $h d r A$ in the ESE cells was also determined. Surprisingly, the $h d r A$ gene was upregulated [14.4 \pm 3.4 times (mean $\pm \mathrm{SD}, n=9$ )] when the ESE cells where cultured with $\mathrm{O}_{2}$ compared with WTOR. The importance of HdrA in the ESE cells was examined by deleting the gene that encodes it. A significant loss of growth capability was observed when the ESE $\Delta h d r A$ strain was grown in pyruvate/sulfate-free medium under continuous $0.65 \% \quad \mathrm{O}_{2}$ sparging compared with the ESE strain (Fig. 1D). However, the growth behaviours of the ESE and ESE $\Delta$ hdrA strains were highly similar when cultured in lactate/sulfate-limiting medium under continuous $\mathrm{O}_{2}$-sparging (data not shown). Thus, HdrA seems to be critical for $\mathrm{O}_{2}$ respiration when pyruvate is used as an electron donor but not with lactate. These results agree with data indicating that $\mathrm{HdrA}$ is more important for pyruvate-based than lactate-based energy metabolism (Meyer et al., 2014; Price et al., 2014; Ramos et al., 2015).

Mutations upstream of the tetR gene were detected in the genome of both the ES5 and ESE strains. Compared with WTOR, the expression of tetR, as determined by qPCR, was slightly higher in both the ES5 and ESE strains cultured with $\mathrm{O}_{2}[3.7 \pm 0.5$ and $3.0 \pm 0.6$ times (mean $\pm \mathrm{SD}, n=9$ ) respectively]. Thus, the mutations identified upstream of the tetR gene induced a change in its expression that would

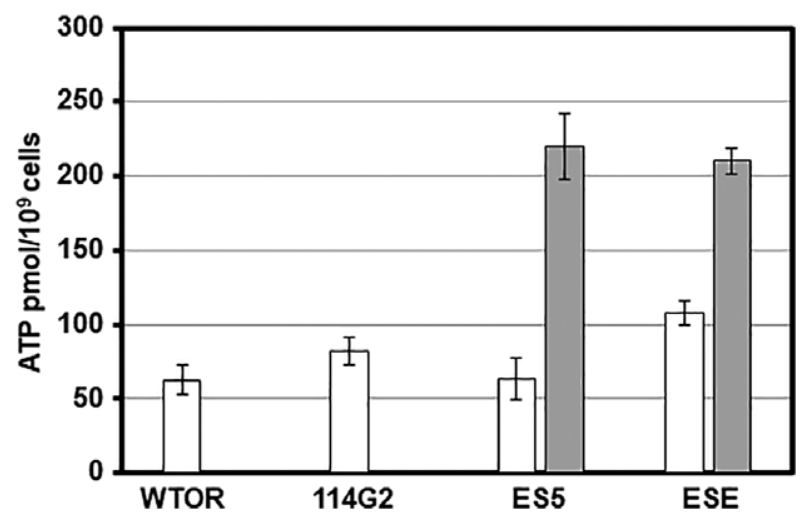

Fig. 3. Intracellular ATP concentration of the cells grown in pyruvate/ sulfate medium under anaerobic conditions (white bars) or in pyruvate/sulfate-free medium under continuous $0.65 \% \mathrm{O}_{2}$-sparging (grey bars). Concentrations were determined in three independent cell preparations. Error bars are the SDs in the measurements. contribute to the metabolic variation in the ES strains. Transcriptomic analysis is required to identify additional transcriptional variations in the ES strains.

\section{Discussion}

Sulfate-reducing bacteria, especially Desulfovibrio species, are among the most aerotolerant anaerobic microorganisms and have been subjected to numerous studies to identify the molecular and cellular mechanisms involved in their aerotolerance capability. While the response of Desulfovibrio species to a transient oxidative stress is well documented, only a few studies examining their growth under continuous exposure to oxidative conditions have been reported (Johnson et al., 1997; Ramel et al., 2015). In this study, via $\mathrm{O}_{2}$-driven experimental evolution, Desulfovibrio vulgaris Hildenborough strains, evolved to grow under continuous $0.65 \%$ oxygensparging corresponding to $7.7 \mu \mathrm{M}$ of dissolved oxygen at $33{ }^{\circ} \mathrm{C}$, were obtained. This concentration is 32 -fold greater than that tolerated by the ancestral $D v H$ strain (Ramel et al., 2015). In addition to their increased aerotolerance, we have unambiguously demonstrated that the $\mathrm{O}_{2}$-evolved strains are capable of a true oxygen respiratory process that leads to oxidative phosphorylation and permits growth. The oxidation of molecular hydrogen or organic compounds coupled to oxygen reduction has been demonstrated in several Desulfovibrio species (Dannenberg et al., 1992). Proton gradient formation and energy production with hydrogen and oxygen as an electron donor and acceptor, respectively, have already been shown in Desulfovibrio desulfuricans (Fitz and Cypionka, 1989; Cypionka, 2000). However, oxygen reduction was never associated with growth. Weak growth (no more than one doubling) of Desulfovibrio desulfuricans and Desulfobacterium autotrophicum with $\mathrm{O}_{2}$ as an electron acceptor has been reported, but it was accompanied by a rapid loss of cell motility and viability (Marschall et al., 1993). Recently, it has been observed that the magnetotactic bacterium Desulfovibrio magneticus forms a band of cells at the oxic-anoxic interface in semi-solid oxygengradient medium (Lefevre et al., 2016). Thus, the authors proposed that this bacterium used oxygen as an electron acceptor, but they did not provide an accurate characterization. An aerobic lifestyle has been proposed for the cable bacteria, members of the anaerobic Desulfobulbacceae family. These multicellular filamentous bacteria have been shown to mediate long-distance (centimetre scale) electron transport from sulfide to oxygen in both marine and freshwater sediments (Schauer et al., 2014; Risgaard-Petersen et al., 2015). Electrons are generated from sulfide oxidation in cells at one end, pass through internal insulated wires to cells at the other end where they are used to reduce oxygen (Pfeffer et al., 2012). 


\section{M. Schoeffler et al.}

However, this atypical aerobic lifestyle raises interesting questions about energy conservation and cell differentiation, since sulfide oxidation and oxygen reduction do not occur in the same cell. Consequently, efficient growth linked to oxygen respiration in a pure culture of any SRB has never been clearly demonstrated before. Therefore, the $\mathrm{O}_{2}$-evolved strains obtained and characterized in this study represent the first example of a Desulfovibrio species exhibiting an energy metabolism based on oxygen respiration that confers the capability of efficient and perennial true $\mathrm{O}_{2}$ respiratory growth. This new capability was obtained after a limited number of generations (114 generations) and a few genomic mutations. Two distinct genotypes were obtained: a major genotype characterized by the absence of the GEl as well as a frameshift mutation in the hdrA gene and an insertion in the regulatory sequence of the tetR encoding gene, and a minor genotype characterized by the presence of the GEI and a deletion in the regulatory expression sequence of the tetR encoding gene. These genotypes resulted from both the selection of a pre-existing polymorphism in the ancestral $D v \mathrm{H}$ and the occurrence of new mutations that rapidly arose after a low number of generations. Polymorphic loci and a rapid selective sweep of pre-existing mutations within the first 100 generations followed by the slow fixation of new mutations has been observed in the experimental evolution of $D$. vulgaris Hildenborough under salt stress for up to 5000 generations (Zhou et al., 2015; Zhou et al., 2017). The authors identified 11 mutations within the first 1200 generations (Zhou et al., 2015) and an additional 25 after 5000 generations, as well as large deletions in both the chromosome and the plasmid (Zhou et al., 2017). Even if the experimental evolution under $\mathrm{O}_{2}$ selective pressure reported here had been conducted for a much lower generation number, mutation selection from pre-existing polymorphisms (i.e., the DVU2402 mutation) and genome reduction (i.e., loss of the GEI) can highlight a common phenomenon in adaptive evolution.

$\mathrm{DvH}$ took two distinct routes of evolution to acquire the capability of $\mathrm{O}_{2}$ respiration. The first, as represented by the ES5 strain, primarily involved the inactivation of the HdrA protein and the loss of the GEI, while the second, represented by the ESE strain, was associated with the overexpression of the hdrA gene. The hdrA gene (DVU2402) is part of the $h d r$-flx operon, which encodes the flavin oxidoreductase FIXABCD and the heterodisulfide reductase HdrABC (Heidelberg et al., 2004; Ramos et al., 2015). In $D$. alaskensis G20, the Flx-Hdr complex is involved in pyruvate-based energy metabolism (Meyer et al., 2014). This complex bifurcates electrons from NADH to DsrC, part of the dissimilatory sulfite reductase DsrABC, and to ferredoxin, allowing an increased yield of reduced ferredoxin, which can be used by an ion-pumping ferredoxin:NADH oxidoreductase (Rnf) to pump ions into the periplasm and
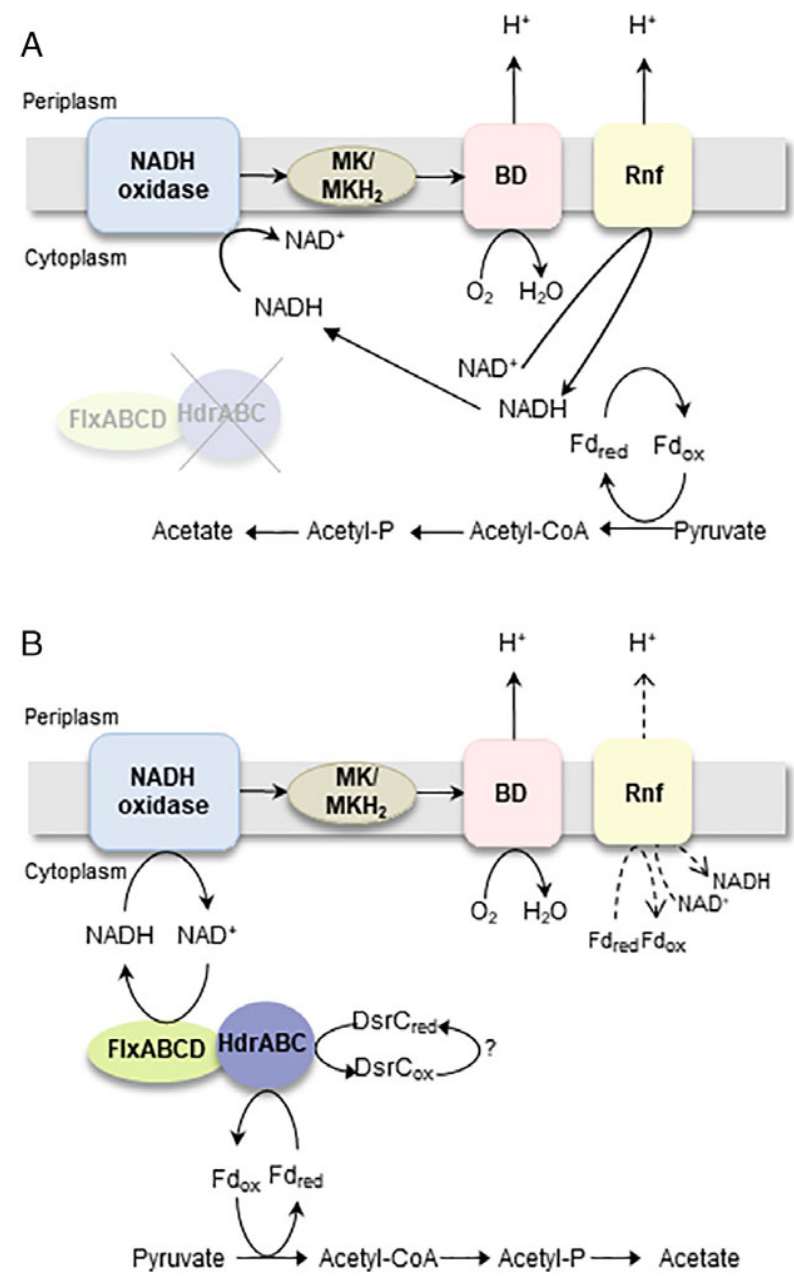

Fig. 4. The central role of $\mathrm{HdrA}$ in the pyruvate-based $\mathrm{O}_{2}$ respiratory growth for ES5 (A) and ESE (B) strains. BD: BD quinol oxidase, Rnf: ferredoxin:NADH oxidoreductase complex, MK/MKH2: menaquinol pool, HdrABC: heterodisulfide reductase complex, FIxABCD: flavin oxidoreductase, Fdred/ox: reduced/oxidized ferredoxin, dsrC: dissimilatory sulfite reductase $\mathrm{C}$. Thick arrows correspond to major fluxes and dashed arrows to minor fluxes.

participate in ion gradient generation (Meyer et al., 2014; Price et al., 2014). The Flx-Hdr complex can also operate in reverse in $D v \mathrm{H}$, reducing $\mathrm{NAD}^{+}$to regenerate oxidized ferredoxin (Ramos et al., 2015). Therefore, the central role of $\mathrm{HdrA}$ in the pyruvate-based $\mathrm{O}_{2}$ respiratory growth for the $\mathrm{ES}$ strains is highlighted in Fig. 4.

In the ES5 strain (Fig. 4A), because of the absence of a functional Flx-Hdr complex, the NADH generated would primarily be re-oxidized by the membrane-bound NADH oxidase, which, in turn, would reduce the menaquinone pool (Ramel et al., 2013). Menaquinol would be then oxidized by the bd quinol oxidase, which reduces $\mathrm{O}_{2}$ in water and thus contributes to the proton motive force. The absence of the GEI, which includes the gene encoding the NADH-dependent ROO1 that permits cytoplasmic $\mathrm{O}_{2}$ reduction without energy conservation, would enhance the efficiency of this $\mathrm{O}_{2}$ respiratory process by 
increasing the reduced NADH pool available for membrane-bound oxygen reduction. In the ESE strain (Fig. 4B), the $h d r$-flx operon is overexpressed, and thus, the Flx-Hdr complex would operate in reverse, regenerating oxidized ferredoxin and reducing $\mathrm{NAD}^{+}$that, in turn, will be used by the bd quinol oxidase for $\mathrm{O}_{2}$ respiration as described above. However, phenotypic analyses have shown that the absence of the GEl and hdrA mutation are not the unique factors involved, and even if they appeared early during the laboratory evolution experiment (19 generations), a fine-tuning of metabolism must have occurred during the continuation of the experiment (till 114 generations), probably in relationship with TetR, to make the $\mathrm{O}_{2}$ respiratory process as efficient and perennial for growth as the sulfate respiration.

These ES strains are the first sulfate-reducing bacteria that exhibit both true oxygen and sulfate respiratory processes. The $\mathrm{O}_{2}$-driven experimental evolution of $\mathrm{DvH}$ led to a lifestyle change of this anaerobic microorganism, allowing it to switch from sulfate to oxygen respiratory growth. This capability, acquired after only a limited number of mutations, should be related to the presence of all enzymatic systems required for both oxygen and sulfate respiration in $\mathrm{DvH}$, and we propose that a rearrangement of metabolite fluxes, especially that of $\mathrm{NAD}^{+} / \mathrm{NADH}$, ultimately enables the optimization of $\mathrm{O}_{2}$ respiration to sustain growth. The data presented in this study provide clues to understand the metabolic versatility of microorganisms at the boundary between aerobic and anaerobic lifestyles.

\section{Experimental procedures}

\section{Bacterial growth conditions}

The culture media were based on medium $C$ as previously described (Postgate et al., 1984) but varied depending on the carbon source and sulfate concentration. Lactate/sulfate medium contained $37 \mathrm{mM}$ lactate and $32 \mathrm{mM}$ sulfate while lactate/sulfate-limiting medium contained $37 \mathrm{mM}$ lactate and $9 \mathrm{mM}$ sulfate. Sulfate-free medium was prepared the same way as above except that sodium sulfate was omitted and $\mathrm{MgCl}_{2}$ and $\mathrm{FeCl}_{2}$ were used to replace the corresponding metal sulfate salts. In this medium, no sulfate could be detected by ion chromatography. Pyruvate $(40 \mathrm{mM})$ was used instead of lactate when indicated. All the strains were cultured at $33{ }^{\circ} \mathrm{C}$ in Hungate tubes containing $10 \mathrm{ml}$ of medium. All the strains were stored in liquid nitrogen from cultures grown in lactate/sulfate medium. For each condition, two successive cultures were performed before analysing the phenotype. Cultures were either grown under anaerobic conditions or under continuous $\mathrm{O}_{2}$-sparging conditions with a gas flow rate of $40 \mathrm{ml} \mathrm{min}{ }^{-1}$ at various oxygen concentrations provided by a gas mixer (PEGAS 4000 MF, Columbus Instruments, USA) as previously described (Ramel et al., 2015). Growth in pyruvate/sulfate-free medium was performed either under anaerobic conditions or under continuous $\mathrm{N}_{2}$ sparging ( $40 \mathrm{ml} \mathrm{min}^{-1}$ ) to lower the hydrogen partial pressure in the culture (Martins et al., 2015). The absence of contamination in the cultures were regularly checked by wet mount microscopy as well as by streaking culture aliquots onto a LuriaBertani agar plate followed by an incubation at $37{ }^{\circ} \mathrm{C}$. The dissolved oxygen concentration was monitored using a Mettler-Toledo M700 recorder equipped with an $\mathrm{O}_{2}$ module ppb 4700 and a calibrated Inpro $6900 \mathrm{O}_{2}$ probe. The growth was monitored by measuring the optical density at $600 \mathrm{~nm}$. The growth rates were estimated by fitting the scatter plots of the logarithmic optical density at $600 \mathrm{~nm}$ from at least four independent experiments to a linear regression. The number of cells per volume unit of culture medium was determined using a Thoma cell counting chamber as previously described (Ramel et al., 2015).

\section{Experimental evolution}

For the $\mathrm{O}_{2}$-driven experimental evolution of $\mathrm{DvH}$, the WTOR strain was successively cultured at $33{ }^{\circ} \mathrm{C}$ in lactate/sulfate medium under continuous $\mathrm{O}_{2}$-sparging conditions at increasing oxygen concentrations (Supporting Information Fig. S1). Briefly, an anaerobic culture in lactate/sulfate medium of a clonal isolate of the ancestral $D v H$ strain (WTOR) was used to inoculate $10 \mathrm{ml}$ of fresh lactate/sulfate medium in Hungate tubes under continuous $0.02 \% \mathrm{O}_{2}$-sparging conditions. Cultures were incubated at $33{ }^{\circ} \mathrm{C}$ until the $\mathrm{OD}_{600 \mathrm{~nm}}$ reached its maximum (early stationary phase) and used to inoculate new fresh lactate/sulfate medium sparged with a higher oxygen concentration. At least two successive cultivations under the same oxygenation condition were performed. The oxygen concentrations used were $0.02 \%, 0.04 \%, 0.08 \%$, $0.12 \%, 0.16 \%, 0.20 \%, 0.25 \%, 0.35 \%, 0.45 \%, 0.55 \%$ and $0.65 \%$. All the cultures were inoculated at $20 \%(\mathrm{v} / \mathrm{v})$. For the anaerobic-driven experimental evolution, the same successive culturing procedure was applied, except that all the cultures were maintained under anaerobic conditions. Subculturing was stopped when the same number of generations as the $\mathrm{O}_{2}$-driven experimental evolution was reached. Samples of the intermediates and final evolved cultures were frozen and stored in liquid nitrogen for further analysis. Clones were isolated from the evolved populations by plating on solid $E$ medium (Postgate et al., 1984) at $33^{\circ} \mathrm{C}$ in an anaerobic chamber (COY) under a $10 \% \mathrm{H}_{2} / 90 \% \mathrm{~N}_{2}$ mixed gas atmosphere. 


\section{Whole-genome sequencing}

Genomic DNA was prepared from $10 \mathrm{ml}$ cultures in lactate/sulfate medium. The cells were harvested by centrifugation at $5700 \mathrm{~g}$ for $15 \mathrm{~min}$ at $4{ }^{\circ} \mathrm{C}$. Total DNA was extracted from the cell pellets using a Wizard Genomic DNA purification kit (Promega) according to the manufacturer's instructions. Illumina sequencing of the total DNA, as well as data analysis to detect potential SNPs and InDels, were conducted on either a GATC Biotech AG (Germany) or a Beckman Coulter Genomics (USA) platform. The genome of $D v H$ (sequence NC_002937.3) was used as a reference.

\section{ATP measurement and oxygen consumption activity in whole cells}

The intracellular ATP concentration was measured using an Intracellular ATP kit (Biothema) according to the manufacturer's instructions. Cultures were grown to mid-log phase in pyruvate/sulfate medium under anaerobic conditions or in pyruvate/sulfate-free medium under continuous $0.65 \% \mathrm{O}_{2}$-sparging. A $20 \mu \mathrm{L}$ aliquot of mid-log phase culture previously diluted 100 -fold was deposited into a black 96 well plate (CORNINGTM 3915), and the reagents were added as indicated by the manufacturer. Luminescence was recorded using a Luminoskan Ascent luminometer (Thermo Scientific), and the data were analysed using the 2.6 version of Ascent software (Thermo Scientific).

\section{Oxygen consumption activity in whole cells}

Cultured cells in lactate/sulfate-limiting medium (80 ml) were centrifuged at $5700 \mathrm{~g}$ at $4{ }^{\circ} \mathrm{C}$ for $15 \mathrm{~min}$. The pellet was resuspended in $40 \mathrm{ml}$ of $150 \mathrm{mM} \mathrm{NaCl}, 100 \mathrm{mM}$ Tris$\mathrm{HCl}$ buffer ( $\mathrm{pH}$ 7.5) (buffer A) previously flushed with $\mathrm{N}_{2}$ to eliminate oxygen and centrifuged again. This washing step was repeated five times to eliminate any trace sulfur that would react with oxygen. Oxygen consumption in the whole cells was measured at $30{ }^{\circ} \mathrm{C}$ in a $2.3 \mathrm{~mL}$ stirred microrespiration chamber filled with air-saturated buffer $A$ using an oxygen microsensor (OX-100) (Unisense). Cells (typically $1.6 \mathrm{mg}$ of protein) were first added to the chamber, and lactate was added at a final concentration of $90 \mathrm{mM}$. The oxygen concentration was recorded using BasicSensor trace software (Unisense). The protein concentrations of the cell suspensions were determined using a Pierce BCA protein assay kit (ThermoScientific) after the addition of $1 \mathrm{M} \mathrm{NaOH}$ to disrupt the cells.

\section{End-product analysis}

Samples of cultures $(600 \mu \mathrm{l})$ were collected immediately after inoculation and at the end of growth and centrifuged for $10 \mathrm{~min}$ at $13400 \mathrm{~g}\left(4^{\circ} \mathrm{C}\right)$. The supernatants were frozen in liquid nitrogen and stored at $-20{ }^{\circ} \mathrm{C}$ until used. Lactate, pyruvate and acetate were quantified using highperformance liquid chromatography (HPLC) as previously described (Ramel et al., 2015). The sulfate concentration was measured on an ion chromatograph (761 Compact IC, Metrohm) equipped with an anion exchange column (Metrosep A Supp1 $250 \times 4.6 \mathrm{~mm}$ ). $\mathrm{Na}_{2} \mathrm{CO}_{3}(3 \mathrm{mM})$ was used as the mobile phase at a flow rate of $1 \mathrm{ml} \mathrm{min}^{-1}$ during the first $8 \mathrm{~min}$, followed by a flow rate of $2.5 \mathrm{ml} \mathrm{min}^{-1}$. The culture supernatants were diluted 10 -fold before injection $(20 \mu \mathrm{l})$. Detection of sulfite and thiosulfate was performed on the same system. Hydrogen sulfide was quantified spectrophotometrically according to the Cline method (Cline, 1969).

\section{TEM analyses}

Cultures were grown to mid-log phase in lactate/sulfatelimiting medium under anaerobic conditions or continuous $0.65 \% \mathrm{O}_{2}$-sparging. Cells were collected by centrifugation (3000 g, $5 \mathrm{~min}$, ambient temperature) and resuspended in $100 \mathrm{mM}$ Tris buffer $(\mathrm{pH} 8)$. Five microliters of the bacterial suspension were placed directly on glow discharged carbon coated grids (EMS) for $3 \mathrm{~min}$. The grids were washed with two drops of $2 \%$ aqueous uranyl acetate and stained with a third drop for $1 \mathrm{~min}$. The grids were dried on filter paper, and the samples were analysed using a Tecnai 200KV electron microscope (FEI), and a numeric camera (Eagle, FEI) was used to acquire digital images. The images recorded were then treated using ImageJ software.

\section{Quantitative real-time PCR}

RNA was prepared from $5 \mathrm{ml}$ cultures at mid-log phase after the addition of $5 \mathrm{ml}$ of RNAlater (Thermo Fisher Scientific). The cells were harvested by centrifugation (5700 $\mathrm{g}$ for $15 \mathrm{~min}$ at $4{ }^{\circ} \mathrm{C}$ ). The cell pellets were frozen in liquid nitrogen and stored at $-80{ }^{\circ} \mathrm{C}$ until use. Total RNA was prepared using a Maxwell ${ }^{\circledR} 16$ LEV simplyRNA Blood Kit (Promega) according to the manufacturer's instructions with an extra TURBO DNase (ThermoFisher) digestion step to eliminate any contaminating DNA. The RNA quality was checked using an Experion ${ }^{\mathrm{TM}}$ StdSens Kit (Bio-Rad), and the absence of DNA contamination was confirmed by PCR. Nucleic acids were quantified spectrophotometrically at $260 \mathrm{~nm}$ (NanoDrop 2000C ThermoScience). For cDNA synthesis, $1 \mu \mathrm{g}$ of total RNA and $0.5 \mu \mathrm{g}$ of random primers (Promega) were used with GoScript ${ }^{\mathrm{TM}}$ Reverse transcriptase (Promega) according to the manufacturer's instructions. Quantitative-real time PCR (qPCR) were performed as previously described (Vita et al., 2015). 
The number of copies of roo1 (DVU2014) and roo2 (DVU3185) were determined by qPCR on genomic DNA prepared from $10 \mathrm{ml}$ cultures as described above. Pure $D v H$ genomic DNA was used as the standard, and a technical duplicate was performed for each point. The amplification efficiencies for each primer pair ranged between $75 \%$ and $100 \%$. All the primer pairs used for qPCR are reported in Supporting Information Table S3.

\section{Construction of the $\Delta$ hdrA deletion mutant strains}

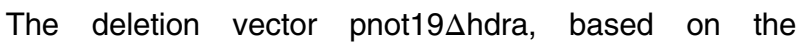
pNOTCm $\Delta$ (Vita et al., 2015) vector backbone, was constructed by the direct transformation of PCR products into E. coli (You et al., 2012) using specific primers pairs described in Supporting Information Table S3. It was then transferred to either the $D v \mathrm{H} \mathrm{GEI}^{-}$or ESE strain by electro-transformation as previously described (Vita et al., 2015). After electro-transformation, the cell/DNA mixture was transferred to $10 \mathrm{ml}$ of lactate/sulfate-limiting medium in Hungate tubes and cultured at $33^{\circ} \mathrm{C}$ for $5 \mathrm{~h}$ before the addition of thiamphenicol $\left(30 \mu \mathrm{g} \mathrm{ml}^{-1}\right)$. Deletion mutant strains were isolated as described above and the $h d r A$ deletion genotype was PCR verified.

\section{Acknowledgements}

The authors thank G. Voordouw for providing the $D v \mathrm{H} \mathrm{GEI}^{-}$ strain. This study benefited from the facilities and expertise of the Platform for Microscopy of IMM (A. Kosta and H. Le Guenno). The authors do not have any conflict of interest to declare.

\section{References}

Baumgarten, A., Redenius, I., Kranczoch, J., and Cypionka, H. (2001) Periplasmic oxygen reduction by Desulfovibrio species. Arch Microbiol 176: 306-309.

Canfield, D., and Des Marais, D. (1991) Aerobic sulfate reduction in microbial mats. Science 251: 1471-1473.

Chen, L., Liu, M., LeGall, J., Fareleira, P., Santos, H., and Xavier, A. (1993) Rubredoxin oxidase, a new flavo-hemoprotein, is the site of oxygen reduction to water by the "strict anaerobe" Desulfovibrio gigas. Biochem Biophys Res Commun 193: 100-105.

Cline, J. D. (1969) Spectrophotometric determination of hydrogen sulfide in natural waters. Limnol Oceanogr 14: 454-458.

Cypionka, H. (2000) Oxygen respiration by Desulfovibrio species. Annu Rev Microbiol 54: 827-848.

Cypionka, H., Widdel, F., and Pfennig, N. (1985) Survival of sulfate-reducing bacteria after oxygen stress, and growth in sulfate-free oxygen sulfide gradients. FEMS Microbiol Ecol 31: 39-45.

Dannenberg, S., Kroder, M., Dilling, W., and Cypionka, H. (1992) Oxidation of $\mathrm{H}_{2}$, organic compounds and inorganic sulfur compounds coupled to reduction of $\mathrm{O}_{2}$ or nitrate by sulfate-reducing bacteria. Arch Microbiol 158: 93-99.

Dolla, A., Fournier, M., and Dermoun, Z. (2006) Oxygen defense in sulfate-reducing bacteria. $J$ Biotechnol 126: 87-100.

Figueiredo, M. C., Lobo, S. A., Carita, J. N., Nobre, L. S., and Saraiva, L. M. (2012) Bacterioferritin protects the anaerobe Desulfovibrio vulgaris Hildenborough against oxygen. Anaerobe 18: 454-458.

Fitz, R. M., and Cypionka, H. (1989) A study on electron transport-driven proton translocation in Desulfovibrio desulfuricans. Arch Microbiol 152: 369-376.

Fournier, M., Dermoun, Z., Durand, M., and Dolla, A. (2004) A new function of the Desulfovibrio vulgaris Hildenborough $[\mathrm{Fe}]$ hydrogenase in the protection against oxidative stress. J Biol Chem 279: 1787-1793.

Fournier, M., Aubert, C., Dermoun, Z., Durand, M., Moinier, D., and Dolla, A. (2006) Response of the anaerobe Desulfovibrio vulgaris Hildenborough to oxidative conditions: proteome and transcript analysis. Biochimie 88: 85-94.

Fourçans, A., Ranchou-Peyruse, A., Caumette, P., and Duran, R. (2008) Molecular analysis of the spatio-temporal distribution of sulfate-reducing bacteria (SRB) in Camargue (France) hypersaline microbial mat. Microb Ecol 56: 90-100.

Frazão, C., Silva, G., Gomes, C., Matias, P., Coelho, R., Sieker, L., et al. (2000) Structure of a dioxygen reduction enzyme from Desulfovibrio gigas. Nat Struct Biol 7: 1041-1045.

Fuseler, K., Krekeler, D., Sydow, U., and Cypionka, H. (1996) A common pathway of sulfide oxidation by sulfatereducing bacteria. FEMS Microbiol Lett 144: 129-134.

Heidelberg, J., Seshadri, R., Haveman, S., Hemme, C., Paulsen, I., Kolonay, J., et al. (2004) The genome sequence of the anaerobic, sulfate-reducing bacterium Desulfovibrio vulgaris Hildenborough. Nat Biotechnol 22: 554-559.

Hensgens, C., Santos, H., Zhang, C., Kruizinga, W., and Hansen, T. (1996) Electron-dense granules in Desulfovibrio gigas do not consist of inorganic triphosphate but of a glucose pentakis(diphosphate). Eur $J$ Biochem 242: 327-331.

Johnson, M., Zhulin, I., Gapuzan, M., and Taylor, B. (1997) Oxygen-dependent growth of the obligate anaerobe Desulfovibrio vulgaris Hildenborough. J Bacteriol 179: 5598-5601.

Johnston, S., Lin, S., Lee, P., Caffrey, S., Wildschut, J., Voordouw, J., et al. (2009) A genomic Island of the sulfate-reducing bacterium Desulfovibrio vulgaris Hildenborough promotes survival under stress conditions while decreasing the efficiency of anaerobic growth. Environ Microbiol 11: 981-991.

Keller, K. L., and Wall, J. D. (2011) Genetics and molecular biology of the electron flow for sulfate respiration in Desulfovibrio. Front Microbiol 2: 135.

Krekeler, D., Teske, A., and Cypionka, H. (1998) Strategies of sulfate-reducing bacteria to escape oxygen stress in a cyanobacterial mat. FEMS Microbiol Ecol 25: 89-96.

Lamrabet, O., Pieulle, L., Aubert, C., Mouhamar, F., Stocker, P., Dolla, A., and Brasseur, G. (2011) Oxygen 
reduction in the strict anaerobe Desulfovibrio vulgaris Hildenborough: characterization of two membrane-bound oxygen reductases. Microbiology 157: 2720-2732.

Lefevre, C. T., Howse, P. A., Schmidt, M. L., Sabaty, M., Menguy, N., Luther, G. W., 3rd, and Bazylinski, D. A. (2016) Growth of magnetotactic sulfate-reducing bacteria in oxygen concentration gradient medium. Environ Microbiol Rep 8: 1003-1015.

Lemos, R., Gomes, C., Santana, M., LeGall, J., Xavier, A., and Teixeira, M. (2001) The 'strict' anaerobe Desulfovibrio gigas contains a membrane-bound oxygen-reducing respiratory chain. FEBS Lett 496: 40-43.

Luther, G. W., Findlay, A. J., Macdonald, D. J., Owings, S. M., Hanson, T. E., Beinart, R. A., and Girguis, P. R. (2011) Thermodynamics and kinetics of sulfide oxidation by oxygen: a look at inorganically controlled reactions and biologically mediated processes in the environment. Front Microbiol 2: 62.

Marschall, C., Frenzel, C., and Cypionka, H. (1993) Influence of oxygen on sulfate reduction and growth of sulfatereducing bacteria. Arch Microbiol 159: 168-173.

Martins, M., Mourato, C., and Pereira, I. A. (2015) Desulfovibrio vulgaris growth coupled to Formate-driven $\mathrm{H}_{2}$ production. Environ Sci Technol 49: 14655-14662.

Meyer, B., Kuehl, J. V., Price, M. N., Ray, J., Deutschbauer, A. M., Arkin, A. P., and Stahl, D. A. (2014) The energy-conserving electron transfer system used by Desulfovibrio alaskensis strain G20 during pyruvate fermentation involves reduction of endogenously formed fumarate and cytoplasmic and membrane-bound complexes, Hdr-Flox and Rnf. Environ Microbiol 16: 3463-3486.

Minz, D., Fishbain, S., Green, S., Muyzer, G., Cohen, Y., Rittmann, B., and Stahl, D. (1999) Unexpected population distribution in a microbial mat community: sulfate-reducing bacteria localized to the highly oxic chemocline in contrast to a eukaryotic preference for anoxia. Appl Environ Microbiol 65: 4659-4665.

Mukhopadhyay, A., Redding, A., Joachimiak, M., Arkin, A., Borglin, S., Dehal, P., et al. (2007) Cell-wide responses to low-oxygen exposure in Desulfovibrio vulgaris Hildenborough. J Bacteriol 189: 5996-6010.

Newport, P. J., and Nedwell, D. B. (1988) The mechanisms of inhibition of Desulfovibrio and Desulfotomaculum species by selenate and molybdate. J Appl Bacteriol 65: 419-423.

Pereira, I. A., Ramos, A. R., Grein, F., Marques, M. C., da Silva, S. M., and Venceslau, S. S. (2011) A comparative genomic analysis of energy metabolism in sulfate reducing bacteria and archaea. Front Microbiol 2: 69.

Pfeffer, C., Larsen, S., Song, J., Dong, M., Besenbacher, F., Meyer, R. L., et al. (2012) Filamentous bacteria transport electrons over centimetre distances. Nature 491: 218-221.

Postgate, J., Kent, H., Robson, R., and Chesshyre, J. (1984) The genomes of Desulfovibrio gigas and $D$. vulgaris. $J$ Gen Microbiol 130: 1597-1601.

Price, M. N., Ray, J., Wetmore, K. M., Kuehl, J. V., Bauer, S., Deutschbauer, A. M., and Arkin, A. P. (2014) The genetic basis of energy conservation in the sulfatereducing bacterium Desulfovibrio alaskensis G20. Front Microbiol 5: 577.
Ramel, F., Brasseur, G., Pieulle, L., Valette, O., HirschlerRéa, A., Fardeau, M. L., and Dolla, A. (2015) Growth of the obligate anaerobe Desulfovibrio vulgaris Hildenborough under continuous low oxygen concentration sparging: impact of the membrane-bound oxygen reductases. PLoS One 10: e0123455.

Ramel, F., Amrani, A., Pieulle, L., Lamrabet, O., Voordouw, G., Seddiki, N., et al. (2013) Membrane-bound oxygen reductases of the anaerobic sulfate-reducing Desulfovibrio vulgaris Hildenborough: roles in oxygen defence and electron link with periplasmic hydrogen oxidation. Microbiology 159: 2663-2673.

Ramos, A. R., Grein, F., Oliveira, G. P., Venceslau, S. S., Keller, K. L., Wall, J. D., and Pereira, I. A. (2015) The FIxABCD-HdrABC proteins correspond to a novel NADH dehydrogenase/heterodisulfide reductase widespread in anaerobic bacteria and involved in ethanol metabolism in Desulfovibrio vulgaris Hildenborough. Environ Microbiol 17: 2288-2305.

Risatti, J., Capman, W., and Stahl, D. (1994) Community structure of a microbial mat: the phylogenetic dimension. Proc Natl Acad Sci USA 91: 10173-10177.

Risgaard-Petersen, N., Kristiansen, M., Frederiksen, R. B., Dittmer, A. L., Bjerg, J. T., Trojan, D., et al. (2015) Cable bacteria in freshwater sediments. Appl Environ Microbiol 81: 6003-6011.

Santana, M. (2008) Presence and expression of terminal oxygen reductases in strictly anaerobic sulfate-reducing bacteria isolated from salt-marsh sediments. Anaerobe 14: 145-156.

Santos, H., Fareleira, P., Xavier, A., Chen, L., Liu, M., and LeGall, J. (1993) Aerobic metabolism of carbon reserves by the "obligate anaerobe" Desulfovibrio gigas. Biochem Biophys Res Commun 195: 551-557.

Sass, H., Berchtold, M., Branke, J., König, H., Cypionka, H., and Babenzien, H. (1998) Psychrotolerant sulfatereducing bacteria from an oxic freshwater sediment, description of Desulfovibrio cuneatus sp. nov. and Desulfovibrio litoralis sp. nov. Syst Appl Microbiol 21: 212-219.

Schauer, R., Risgaard-Petersen, N., Kjeldsen, K.U., Tataru Bjerg, J.J., B Jørgensen, B., Schramm, A., and Nielsen, L. P. (2014) Succession of cable bacteria and electric currents in marine sediment. ISME J 8: 1314-1322.

Thauer, R., Stackebrandt, E., and Hamilton, A. (2007)Energy metabolism and phylogenetic diversity of sulphatereducing bacteria . In Sulphate-Reducing Bacteria: Environmental and Engineered Systems, Barton, L., and Hamilton, A. (eds). Cambridge: Cambridge University Press, pp. 1-38.

Thauer, R. K., Jungermann, K., and Decker, K. (1977) Energy conservation in chemotrophic anaerobic bacteria. Bacteriol Rev 41: 100-180.

Vita, N., Hatchikian, E. C., Nouailler, M., Dolla, A., and Pieulle, L. (2008) Disulfide bond-dependent mechanism of protection against oxidative stress in pyruvate-ferredoxin oxidoreductase of anaerobic Desulfovibrio bacteria. Biochemistry 47: 957-964.

Vita, N., Valette, O., Brasseur, G., Lignon, S., Denis, Y., Ansaldi, M., et al. (2015) The primary pathway for lactate oxidation in Desulfovibrio vulgaris. Front Microbiol 6: 606. 
Voordouw, G. (2002) Carbon monoxide cycling by Desulfovibrio vulgaris Hildenborough. J Bacteriol 184: 5903-5911.

You, C., Zhang, X. Z., and Zhang, Y. H. (2012) Simple cloning via direct transformation of PCR product (DNA Multimer) to Escherichia coli and Bacillus subtilis. Appl Environ Microbiol 78: 1593-1595.

Zhou, A., Hillesland, K. L., He, Z., Schackwitz, W., Tu, Q., Zane, G. M., et al. (2015) Rapid selective sweep of preexisting polymorphisms and slow fixation of new mutations in experimental evolution of Desulfovibrio vulgaris. ISME J 9: 2360-2372.

Zhou, A., Lau, R., Baran, R., Ma, J., von Netzer, F., Shi, W., et al. (2017) Key metabolites and mechanistic changes for salt tolerance in an experimentally evolved sulfatereducing bacterium. $m$ Bio 8 : e01780-17.

\section{Supporting Information}

Additional Supporting Information may be found in the online version of this article at the publisher's web-site:

Fig. S1. Experimental evolution process. Apparatus for growth in the presence of defined $\mathrm{O}_{2}$ concentrations (A). Experimental design to establish the desired continuous $\mathrm{O}_{2}$-sparging (B). Illustration of the experimental workflow (C). A clonal isolate of the ancestral $D v H$ (WTOR) strain was grown in lactate/sulfate medium (medium $\mathrm{C}$ ). This culture was then used to initiate the evolution by inoculating it in medium $\mathrm{C}$ under $0.02 \% \mathrm{O}_{2}$-sparging. The $\mathrm{O}_{2}$ concentration was successively increased during the course of evolution, reaching an $\mathrm{O}_{2}$ concentration of $0.65 \%$ after 114 generations (114 g). For the anaerobicdriven experimental evolution, the same successive culturing procedure was applied under anaerobic conditions. At the end of both evolutionary periods, clones were isolated from the evolved population. Genome of six $\mathrm{O}_{2}$ evolved (ESC, D, E and ES3, 4 and 5) and 3 anaerobicevolved clones (114G1, 2 and 3) and the WTOR strain were sequenced. Among them, characterization was conducted on the ESE, ES5 and 114G2 strains.

Fig. S2. Confirmation of mutations in the intergenic region of Dvu1690 (tetR gene): PCR products of the intergenic region upstream DvU1690 (tetR gene) using the couple of primers DVU1690Left and DVU1690Right (see Table S3) using as template the evolved population at various steps of the $\mathrm{O}_{2}$-driven experimental evolution as well as the ES5 and ancestral DvH (WTOR) strains. Lane M: size markers (A). Sanger sequencing of the region corresponding to the deletion in the intergenic region of tetR (see Table) in the evolved population at various steps of the $\mathrm{O}_{2}$-driven experimental evolution as well as in the ESE and ancestral DvH (WTOR) strains. Chromatograms of the sequences are shown; the stars indicate the deleted nucleotides (B).
Fig. S3. Growth curves of ES5 (up triangle), ESE (down triangle), 114G2 (circle) and WTOR (square) strains in lactate/sulfate medium under anaerobic conditions (A), in lactate/sulfate medium under continuous $0.65 \% \quad \mathrm{O}_{2}$ sparging (B), in lactate/sulfate-limiting medium under anaerobic conditions (C) and in lactate/sulfate-limiting medium under continuous $0.65 \% \mathrm{O}_{2}$-sparging (D). The growth curves were obtained from at least four independent experiments. Error bars are the SDs in the measurements.

Fig. S4. Growth curves of ES5 (up triangle), ESE (down triangle), 114G2 (circle) and WTOR (square) strains in pyruvate $40 \mathrm{mM} /$ sulfate $40 \mathrm{mM}$ medium under anaerobic conditions (A) and in pyruvate/sulfate-free medium under anaerobic conditions (B). The growth curves were obtained from at least four independent experiments. Error bars are the SDs in the measurements.

Fig. S5. Substrate quantitation. Percent of lactate consumed $(A)$, Molar growth yield on lactate $\left(Y_{\text {lac }}\right)(B)$ and Ratio lactate consumed/sulfate reduced (C). Strains were cultured until the stationary phase, in lactate/sulfate medium under anaerobic conditions for the WTOR and $114 \mathrm{G} 2$ strains and under continuous $0.65 \% \mathrm{O}_{2}$-sparging for the ES5 and ESE strains. Molar growth yields are expressed in $10^{12}$ cells $/ \mathrm{mol}$ of lactate consumed. Error bars are the SDs in the measurements (at least $n=3$ ).

Fig. S6. Growth curves of ESE (square) and sulfate quantitation (open circle) in lactate/sulfate-limiting medium under continuous $0.65 \% \quad \mathrm{O}_{2}$-sparging. The curves were obtained from duplicate experiments.

Fig. S7. Effect of molybdate on the growth of the ES5 (grey bars) and ESE (white bars) strains. Culture were performed in lactate $(37 \mathrm{mM}) /$ sulfate $(9 \mathrm{mM})$ medium under anaerobic conditions or under continuous $0.65 \%$ $\mathrm{O}_{2}$ sparging $\left(+\mathrm{O}_{2}\right)$ with $\left(+\mathrm{MoO}_{4}\right)$ or without $\left(-\mathrm{MoO}_{4}\right)$ the addition of $250 \mu \mathrm{M} \mathrm{MoO}_{4}$ (A). Culture were performed in pyruvate $(40 \mathrm{mM}) /$ sulfate $(9 \mathrm{mM})$ medium under anaerobic conditions or in pyruvate $(40 \mathrm{mM}) /$ sulfate-free medium under continuous $0.65 \% \mathrm{O}_{2}$ sparging $\left(+\mathrm{O}_{2}\right)$ with $\left(+\mathrm{MoO}_{4}\right)$ or without $\left(-\mathrm{MoO}_{4}\right)$ the addition of $250 \mu \mathrm{M} \mathrm{MoO}_{4}$ (B). At the end of the growth, cells were collected, and the protein concentration was determined.

Fig. S8. Comparison of the distribution of the cell lengths of ES5, ESE, 114G2 and WTOR cultured in lactate/sulfate-limiting medium under anaerobic conditions and under continuous $0.65 \% \mathrm{O}_{2}-$ sparging $\left(+\mathrm{O}_{2}\right)$. The average cell length was determined from $>150$ cell measurements.

Fig. S9. Effect of KCN on the growth of the ES5 (A) and ESE (B) strains. The white and grey bars correspond to the $\mathrm{OD}_{600 \mathrm{~nm}}$ at the inoculation time and $\mathrm{OD}_{600 \mathrm{~nm}}$ at the end of the growth respectively. Culture were performed in pyruvate $(40 \mathrm{mM}) /$ sulfate $(9 \mathrm{mM})$ medium under 
14 M. Schoeffler et al.

anaerobic conditions with $(+\mathrm{KCN})$ or without $(-\mathrm{KCN})$ the addition of $6 \mathrm{mM} \mathrm{KCN}$ or in pyruvate $(40 \mathrm{mM}) /$ sulfate free medium under continuous $0.65 \% \quad \mathrm{O}_{2}$ sparging with $(+\mathrm{KCN})$ or without $(-\mathrm{KCN})$ the addition of $6 \mathrm{mM} \mathrm{KCN}$. The values are the means of 3 independent cultures.
Table S1. NGS data of the sequenced genome strains. Table S2. Mutations identified in DvH WTOR strain compared to the NCBI D. vulgaris Hildenborough reference sequence NC_002937.3

Table S3. Oligonucleotide primers used. 